\title{
Specialized fast track: a sustainable model to improve emergency department patient flow
}

\author{
Emilpaolo Manno ${ }^{* 1}$, Marco Pesce ${ }^{1}$, Umberto Stralla ${ }^{1}$, Federico Festa ${ }^{1}$, Silvio Geninatti ${ }^{2}$, Maria Fausta Balzarro ${ }^{2}$, \\ Daniele Di Leo ${ }^{1}$, Barbara Gelain ${ }^{1}$ \\ ${ }^{1}$ Maria Victoria Hospital, Italy \\ ${ }^{2}$ ASL TO2, Italy
}

Received: April 27, 2015

Accepted: June 16, 2015

Online Published: June 30, 2015

DOI: $10.5430 /$ jha.v4n5p40

URL: http://dx.doi.org/10.5430/jha.v4n5p40

\begin{abstract}
Objective: Emergency department (ED) overcrowding is a hospital-wide problem that demands a whole-hospital solution. We developed and implemented a fast track model for streaming ED patients with low-acuity illness or injury to specialized care areas (gynecology-obstetrics, orthopedics-trauma, pediatrics, and primary care) staffed by existing specialist resources with access to general ED services. The study aim was to determine whether streaming of ED visits into specialized fast track areas increased operational efficiency and improved patient flow in a mixed adult and pediatric ED without incurring extra costs.

Methods: We retrospectively reviewed the ED discharge records of patients who were mainstreamed or fast tracked during the 3-year period from 1 January 2010 through 31 December 2012. ED visits were identified according to a five-level triage scheme; performance indicators were compared for: wait time, length of stay, leave before being seen and revisit rates.

Results: A reduction in wait time, length of stay, and leave before being seen rate was seen with fast track streaming $(p<.01)$. These improvements were achieved without additional medical and nurse staffing.

Conclusions: Specialized fast track streaming helped us meet patients' care needs and contain costs. Lower-acuity patients were seen quickly by a specialist and safely discharged or admitted to the hospital without diverting resources from patients with high-acuity illness or injury. Involvement of all stakeholders in seeking a sustainable solution to ED crowding as a hospital-wide problem was key to enhancing cooperation between the ED and the hospital units.
\end{abstract}

Key Words: Emergency department, Fast track, Urgent care, Healthcare policy

\section{INTRODUCTION}

Like other European countries, Italy has a universalistic health care system that provides both basic health care and lifesaving medical services. According to recent government figures, the National Health System (NHS) expenditure increased from $€ 108,891$ billion in 2008 to $€ 112,039$ billion in $2011^{[1]}$ and it is projected to increase by $1.9 \%$ per year on average until 2017. ${ }^{[2]}$ The 2013 study also reported that expenditure as a proportion of gross domestic product (GDP) is
7.6\%. But as GDP continues to shrink, the share tagged to it is forecast to decrease to $6.7 \%$, leaving fewer funds to cover the country's growing health care needs. ${ }^{[2,3]}$ Following the hike in regional copayment rates ${ }^{[4]}$ for routine health services in 2012, the number of nonurgent emergency department (ED) visits has surged, adding to the recurrent problem of ED overcrowding for unscheduled nonurgent care that diverts resources from the severely ill or injured..$^{[5-10]}$ Moreover, although more and sicker patients seek care, ${ }^{[11,12]}$ ED and

*Correspondence: Emilpaolo Manno; Email: emilpaolo.manno@aslto2.piemonte.it; Address: Maria Victoria Hospital, Italy. 
inpatient capacity has actually declined in past decades, ensuing in permanent ED overcrowding where inflow is greater than outflow. ${ }^{[9,13-16]}$ The rate of ED visits after hospital discharge as well as the rate of revisit in ED are largely unknown, ${ }^{[17-19]}$ but can represent a significant problem as well as patients presenting to the ED but who leave before being seen (LBBS) by an ED physician. The proportion of LBBS varies from $1.4 \%$ to $2.9 \%$ in the United States ${ }^{[20,21]}$ and from $0.9 \%$ to $7.4 \%$ in Europe. ${ }^{[22,23]}$ In the current era of limited resources, ED overutilization has compounded the problem of adequate staffing in response to variability during peak evening hours and on weekends when ancillary services are not normally available. Current evidence has shown that, among other process interventions, fast track streaming can reduce overcrowding and increase patient satisfaction. ${ }^{[24-26]}$

In 2008, jointly with the hospital-planning department, we developed a sustainable model that would meet patients' care needs within the limited resources available. To do this, we involved all stakeholders in implementing special- ized fast track areas in the ED. The ED was reorganized to optimize patient flow with a pivotal role assigned to the triage nurse in decision-making processes, including initial patient assessment and assignment to a fast track area. Before stepping into their new role, the ED nurses received training in pediatric and obstetric-gynecologic triage assessment, which included simulation sessions supervised by the course tutors (pediatricians and gynecologist). Care pathways and triage schemes to ensure early access to an appropriate health provider are mandated by national law ${ }^{[27]}$ and regional guidelines. ${ }^{[28]}$ A five-level triage scheme with time references is generally used ${ }^{[29]}$ (Red code: no wait; Yellow code: $\leq 15$ minutes wait; Green 30 code: $\leq 30$ minutes wait; Green 60 code: $\leq 60$ minutes wait; White code: when possible). The triage nurse reassesses the patient within a defined time frame (15 min, $30 \mathrm{~min}, 60 \mathrm{~min}$, respectively) or when there is a change in the patient's symptoms. Table 1 presents the triage scale in use at the Maria Victoria Hospital and two other widely used scales.

Table 1. The MVH Triage scale applied in the present study as compared with the CTAS and MTS

\begin{tabular}{|c|c|c|c|c|c|c|c|c|}
\hline \multicolumn{3}{|c|}{ MVH Triage Scale } & \multicolumn{3}{|c|}{ CTAS } & \multicolumn{3}{|c|}{ MTS } \\
\hline Code & Urgency & Wait Time & Code & Urgency & Wait Time & Code & Urgency & Wait Time \\
\hline Red & Emergent & No wait & Level I & Resuscitation & No wait & Red & Immediate & No Wait \\
\hline Yellow & Very urgent & $\leq 15 \min$ & Level II & Emergent & $\leq 15 \min$ & Orange & Very urgent & $\leq 10 \min$ \\
\hline Green 30 & Urgent & $\leq 30 \min$ & Level III & Urgent & $\leq 30 \min$ & Yellow & Urgent & $\leq 1$ hour \\
\hline Green 60 & Less urgent & $\leq 60 \mathrm{~min}$ & Level IV & Less urgent & $\leq 1$ hour & Green & Standard & $\leq 2$ hours \\
\hline White & Non-urgent & When possible & Level V & Non-urgent & $\leq 2$ hours & Blue & Non-urgent & $\leq 4$ hours \\
\hline
\end{tabular}

Note. MVH: Maria Victoria Hospital; CTAS: Canadian Triage \& Acuity Scale; MTS: Manchester Triage Scale

The model is flexible and responsive so that patients initially fast tracked to a specialized area can be mainstreamed with clinical handover back to the ED if necessary. In line with current recommendations, ${ }^{[30]}$ patients are seen in order of arrival in the fast track areas. Four specialized areas were created: pediatrics, obstetrics-gynecology, orthopedics-trauma, and primary care. The process changes involved no additional nursing or medical staff. The only cost was a 6-month triage nurse-training course. To avoid fragmentation of care, fast track physicians admit to the hospital or discharge patients without referring them back to the general ED. This study sought to determine whether specialized fast track streaming increased operational efficiency and improved patient flow in the ED.

\section{METHODS}

\subsection{Study design and oversight}

We performed a retrospective cohort study of patients presenting to the ED of the Maria Victoria Hospital (Turin, Italy) from January 1, 2010 through December 31, 2012. There was no commercial support for this study. The study was approved by the Ethics Committee of our Institution.

\subsection{Study population}

The Maria Victoria Hospital is a 347-bed tertiary teaching hospital located in a central urban area. It provides a comprehensive range of hospital services to a community of over 250,000 people. The annual number of ED visits is consistently high: 95,096 in 2010, 90,145 in 2011, and 89,196 in 2012. There is a broad case-mix, with pediatric patients accounting for $13.9 \%, 14.2 \%$, and $14.9 \%$ of visits in the past 3 years, respectively, and an overall admission rate of $7.7 \%$, $7.7 \%$, and $8.0 \%$, respectively. Prior to implementation of the fast track system, inclusion and exclusion criteria were strictly defined (see Table 2) and the ED nurses completed a 6-month training course.

Specialized fast track streaming began in November 2008 starting with the pediatric area and was progressively ex- 
tended to obstetrics-gynecology, orthopedics-trauma, and primary care areas. It operates 24 hours a day, except for the orthopedic-trauma fast track which is open daily from 8.00 AM to 8.00 PM; outside these hours orthopedic-trauma patients are seen in the general ED. On arrival at the ED, patients are assessed by a triage nurse and fast tracked if they meet the inclusion criteria and do not present with exclusion criteria. To avoid fragmentation of care, patients are discharged home or admitted to an inpatient unit directly from a fast track area.

Table 2. Inclusion and exclusion criteria for assignment to a specialized fast track area

\begin{tabular}{|c|c|c|}
\hline & Inclusion criteria & Exclusion criteria \\
\hline Pediatrics & Green and white codes: age $<14$ years & $\begin{array}{l}\text { Red and yellow codes, age }>14 \\
\text { years, trauma, wounds }\end{array}$ \\
\hline Obstetrics-Gynecology & $\begin{array}{l}\text { Green and white codes: women, impairment of reproductive system; STI; } \\
\text { probable UTI; pregnant women with pregnancy-related problem; fetal urgencies }\end{array}$ & Red and yellow codes \\
\hline Orthopedics-Trauma & $\begin{array}{l}\text { Green and white codes: limb injury without neurovascular compromise; low } \\
\text { back pain (without trauma, fever, neurologic deficit, age > } 40 \text { years); minor } \\
\text { lacerations not involving deep structures; scalp laceration (no loss of } \\
\text { consciousness or other neurological symptoms); joint sprain/strain }\end{array}$ & $\begin{array}{l}\text { Red and yellow codes: trauma to } \\
\text { the head, chest, abdomen, pelvis, } \\
\text { or spinal column; polytrauma }\end{array}$ \\
\hline Primary Care & $\begin{array}{l}\text { White code: health services that could be normally handled by a primary care } \\
\text { provider; minor contusion and abrasion; skin rash without fever; minor } \\
\text { animal/insect bites without neurovascular or systemic symptoms }\end{array}$ & $\begin{array}{l}\text { Red, yellow green } 30 \text {, green } 60 \\
\text { codes: trauma; acute pain; } \\
\text { workplace accident }\end{array}$ \\
\hline
\end{tabular}

The study population (see Table 3) included patients registered at the ED between January 1, 2010 and December 31,2012 , and included only patients triaged as code green 30 or 60 . Patients triaged as code red or yellow were exclusively assessed in the main ED, whereas those triaged as code white were fast-tracked to one of the fast track areas. Hence, only patients categorized as code green 30 or 60 were seen and treated in either a fast track area or the main ED. In all 108,376 patients were admitted to the general ED and 88,752 to the fast-track areas (total study population 197,128).

Table 3. Demographic characteristics of study population

\begin{tabular}{lll}
\hline & General ED & Speciality Fast Track \\
\hline Overal attendances* $^{*}$ & 95,691 & 95,049 \\
Average daily attendances $^{* *}$ & 873 & 867 \\
Median age-years (IQR) & $490(38)$ & $270(32)$ \\
Gender & & \\
Male-total no. (col\%) & $50,736(53 \%)$ & $38,495(40.5 \%)$ \\
Female-total no. (col\%) & $44,995(47 \%)$ & $56,552(59.5 \%)$
\end{tabular}

"Total number of patient attendances in the study period; ** Average daily number of patient attendances; IQR: interquartile range

\subsection{Study outcomes}

The study sought to determine whether specialized fast track streaming increased operational efficiency and improved patient flow. The primary endpoints were safety as measured by mortality during stay in a fast track area, wait time, length of stay, and number of LBBS patients. The secondary endpoint was appropriateness of patient assignment as measured by revisit rate within 72 hours for the same medical problem.

\subsection{Data collection}

Data were extracted from the ED discharge database (Hippocrates GPI Group, Trento, Italy). Under retrospective observational design, chart review of ED admissions identified: age and sex, triage code, wait time (time from registration at triage to being assessed by an ED physician), length of stay (total time spent in the ED, from registration at triage to discharge home or admission to an inpatient unit), LBBS rate (defined as whether a patient left the ED before being assessed by a physician), revisit rate (number of revisits to the ED within 72 hours for the same problem), mortality among fast-tracked patients, ED disposition (discharge home or admission to a hospital unit).

\subsection{Statistical analysis}

The median wait time and length of stay in the fast-track areas and the general ED were compared. The median test (Brown-Mood method) was used to evaluate statistical significance at an alpha level of .05 of the observed differences. The proportion of LBBS patients and the revisit rate (within 72 hours for the same diagnosis) stratified for fast-track streaming versus general ED were compared and the differences weighed by the $Z$-test for proportions at an alpha level of .05. All statistical analyses were performed using SAS software, version 9.1.3 (SAS Institute Inc. Cary, NC, USA). Descriptive statistics were used for demographic and clinical characteristics.

\section{RESULTS}

Table 1 reports patient characteristics for mainstreamed and fast-tracked patients. The wait time for patients triaged with green 30 code decreased by $7 \mathrm{~min}$ ( 22 to $15 \mathrm{~min} ; p<.01$ ), 
by $1 \mathrm{~min}$ for green 60 code (23 to $22 \mathrm{~min}$; difference not statistically significant) (see Table 4).

Table 4. Median waiting time (min)

\begin{tabular}{|c|c|c|c|}
\hline \multirow{2}{*}{ Triage code } & \multicolumn{2}{|c|}{ Median Time (IQR) } & \multirow{2}{*}{ Difference } \\
\hline & General ED & Speciality Fast Track & \\
\hline Green $60^{*}$ & $23(36)$ & $22(32)$ & -1 \\
\hline Green $30^{* * *}$ & 22 (37) & $15(26)$ & -7 \\
\hline
\end{tabular}

"Brown-Mood Median test n. s.; ${ }^{* *}$ Brown-Mood Median test, $p<.01$; IQR, interquartile range

The length of stay for green 60 code decreased by 46 min (113 to $67 \mathrm{~min} ; p<.01$ ), and by $166 \mathrm{~min}$ (236 to $70 \mathrm{~min}$; $p<.01$ ) for green 30 code (see Table 5). The proportion of patients who left before being seen for the general ED and the fast-track areas are shown in Table 6. The proportion of LBBS patients, irrespective of triage code, was lower for the fast-tracked patients $(p<.01)$. The revisit rate for the same medical problem within 72 hours after ED discharge was $2.43 \%$ for mainstreamed ED patients and $2.42 \%$ for fast-tracked patients (difference not statistically significant)

Table 5. Median length of stay (min)

\begin{tabular}{llll}
\hline \multirow{2}{*}{ Triage code } & \multicolumn{2}{l}{ Median Time (IQR) } & \multirow{2}{*}{ Difference } \\
\cline { 2 - 3 } & General ED & Speciality Fast Track & \\
\hline Green $60^{*}$ & $113(204)$ & $67(86)$ & -46 \\
Green $30^{* *}$ & $236(640)$ & $70(109)$ & -166 \\
\hline
\end{tabular}

"Brown-Mood Median test n. s.; ** Brown-Mood Median test, $p<.01$; IQR, interquartile range

Table 6. Total number and proportion of LBBS

\begin{tabular}{llll}
\hline Triage code & $\begin{array}{l}\text { General ED } \\
\mathbf{n} ; \%{ }^{* *} ;(\mathbf{9 5 \%} \mathbf{C I})\end{array}$ & $\begin{array}{l}\text { Speciality Fast Track } \\
\mathbf{n ; \%}{ }^{* *} ; \mathbf{( 9 5 \% ~ C I )}\end{array}$ & $\begin{array}{l}\text { Difference } \\
\text { between } \\
\text { proportion }\end{array}$ \\
\hline Green $30^{* *}$ & 3,$812 ; 5.6 \%(5.4-5.8)$ & $1452 ; 1.8 \%(1.75-1.93)$ & -3.8 \\
Green $60^{* * *}$ & 1,$355 ; 4.9 \%(4.7-5.2)$ & $249 ; 1.5 \%(1.3-1.7)$ & -3.4 \\
\hline${ }^{*} Z$ test for proportions, $p<.001 ;{ }^{* *}$ proportion of LBBS patients; CI confidence interval
\end{tabular}

\section{DISCUSSION}

ED overcrowding is a growing problem. In 2008, we implemented fast track streaming for patients with low-acuity illness or injury to improve patient flow while fully aware of two main concerns raised by medical specialists and hospital administrators: that fast-tracked patients are at a greater risk of poor outcome and potential harm than those seen in a general ED, and that fast tracking can negatively impact on routine specialist care. Our study, albeit retrospective, shows that in spite of the high volume of fast tracked ED visits over the past 3 years, no mortalities were recorded. This can be related to the accuracy of assessment by triage nurses in assigning appropriate care pathways. To our knowledge, this is the first study to report the outcomes of a hospital-wide effort to mitigate ED overcrowding. Because ED crowding Published by Sciedu Press is closely linked to a hospital's capacity to admit in timely fashion all patients requiring admission, it follows that all units are accountable for providing for admissions from the ED. Specialized fast track streaming is an innovative process model rarely implemented elsewhere in Italy. We found that the model can be efficiently run without additional ED nurse and doctor staffing and without adding resources to specialist units. It has become an integral part of routine specialty care and has garnered satisfaction among staff. There was a significant reduction in wait time, length of stay, and LBBS rates for the fast-track areas; taken together, literature relates these indicators to patient satisfaction. ${ }^{[30]}$ Our hospital administration and ED are presently working together on extending fast-track services to: dentistry, ophthalmology, and otorhinolaryngology services.

Fast track pathways have been devised and implemented as a strategy to reduce overcrowding, wait time of low-acuity patients, and the number of LBBS patients, with a view to enhance system efficiency. ED fast track systems have been shown to work well ${ }^{[23-25]}$ in settings were adequate staff and dedicated treatment areas are available. A further requisite is that the ED organization is structured in such a way as to provide a rapid decision-making process for establishing prompt diagnosis (within 6 hours on average) and transfer to a specialist ward if appropriate. ${ }^{[32]}$ In brief in a flow-based organization a short stay in ED is compatible with optimal diagnosis and orientation. ${ }^{[33]}$ Our data are consistent with the observation that more and more hospital admissions are through the ED. The number of hospital admissions that came through our ED was 7,176 in 2010 (48.0\% of all hospital admissions), 7,459 in 2011 (50.8\%), and 7,814 in 2012 $(54.5 \%)(p<.01)$. The proportion of hospital admissions from the fast track areas was $5.4 \%$, the total ED admission rate was $7.9 \%$. This rate is in line with previous studies, which reported that $5.5 \%$ of patients triaged as being nonurgent require hospital admission after full evaluation. ${ }^{[34]}$ In our study, the hospital admission rate of the initially fast tracked patients was high though they were triaged as having "low priority" illness or injury. Nonetheless, one benefit of our fast track model over traditional use of the ED and conventional fast track streaming is that patients are directed to a different pathway within the ED where they are cared for by specialist staff which can call on ancillary hospital services (imaging, laboratory, consultants) as needed. The decision to admit directly from fast track areas, though the admission process takes time and uses resources, did not clog up the fast track.

The decline in hospital inpatient capacity has led to an increased reliance on interventionist practices in the ED (more orders for imaging, laboratory tests, and initiation of IV 
fluids). This trend has made medical decision-making more complex and ED overcrowding has ensued. With fast track streaming, specialist evaluation can be expedited, thus probably reducing interventionist practices, as shown by the shorter length of stay compared against the general ED in our study. High hospital readmission rates are also linked to circumstances outside the control of the hospital (patients with more severe illness and the socioeconomically disadvantaged). ${ }^{[35]}$ While these factors may influence ED revisit rates, inappropriate care is also a likely cause of revisit and readmission. ${ }^{[36]}$ Measuring the rate of ED visits after inpatient discharge and ED revisits $(3 \%-4 \%$ of unscheduled visits return within 72 hours for the same problem $)^{[36,37]}$ may reveal opportunities to improve care transition and reduce avoidable acute-level use. Our study shows that the revisit rates did not differ between the general ED (2.2\%) and the fast track areas $(2.2 \%)$ In brief, fast track streaming does not increase the probability of revisits, but it is unable to reduce them. Our study population was large (197,128 patients) and the results accrue to evidence that patient flow through a busy ED can be substantially redesigned and that fast track areas can be successfully adapted to many different clinical settings. Following implementation of specialized fast tracks, the flow of patients with low-priority codes improved and the LBBS rate decreased. Differently from conventional fast track strategies, in our model this improvement came without additional specialty medical or nursing staff. Almost certainly there was an opportunity cost paid in time and energy as clinicians had to adapt to the new routine and system. The driving force behind the adoption of the specialized fast track model was a joint departmental and institutional effort to solve ED overcrowding without reducing the quality of care and by relying on already available resources. More generally, a hospitalwide approach serves to reduce the waste that comes from fragmented care. ${ }^{[37]}$ Given the dwindling funds allocated to the national health system and the rising demand of medical services, we think that specialized fast track streaming offers a sustainable solution to curbing health care costs.

\section{Limitations}

It was conducted in a single center and may be not generalizable to other hospitals or settings. We did not study the effect of fast track streaming on other patient-related outcomes such as time to analgesia or antibiotics in patients with pain or pneumonia, respectively, nor did we evaluate the impact of fast track streaming on duration of hospital stay and patient prognosis. The aim was to evaluate the effect the implementation of a fast-track system had on the delivery of emergency care. In addition the clinical severity of the patients seeking treatment was not specifically evaluated in this study. Though the two groups were comparable by triage category they may have differ in severity of illness. Nonetheless this concern is of minor relevance since it does not affect operational efficiency. Because the data were extracted from our hospital databases and because the information system was changed before the beginning of the study, we were unable to determine whether patients were treated at another hospital during the study period nor could we make a historical comparison with data prior to the database system changes.

\section{Conclusions}

The volume of ED admissions cannot be planned. ED overcrowding is inevitable and foster situations in which the severely ill and the less ill compete for available resources. Specialized fast track streaming however, can reduce the number of patients waiting in the general ED, making it a safer place where patients can wait until seen, enabling staff to concentrate on the severely ill or injured, ultimately reducing unnecessary delays and improving the quality of care in the ED. Fast track specialists complete treatment with admission to an inpatient unit or discharge from the hospital. No evidence of a decline in the safety of care, as defined by mortality and revisit rate, was recorded for the fast-tracked patients in this study. Patient satisfaction was reflected by the lower LBBS rates for all fast track areas as compared to the general ED. Fast tracked patients were safely seen in order of arrival, reducing the complexity of the queuing process and length of stay. We think that such a patient-centered organization can help to increase ED operational efficiency and improve patient flow, while avoiding fragmented care without the need for additional nurse or medical staffing.

_economico_finanziaria/documenti_programmatici/sez ione3/def.htlm

[3] Centre for Research on Health and Social Care Management, Bocconi University Milan. Available from: http://www. cergas . uni bocconi.it/wps/allegatiCTP/exsumm2009_finale.pdf

[4] Andrulis DP, Kellermann AL, Hintz EA, et al. Emergency depart- 
ments and crowding in United States teaching hospitals. Ann Emerg Med. 1991; 20: 980-6. http://dx.doi.org/10.1016/S0196-0 644(05) 82976-2

[5] Baker LC, Baker LS. Excess cost of emergency department visits for non-urgent care. Health Aff (Millwood). 1994; 13(5): 162-71. http://dx.doi.org/10.1377/hlthaff.13.5.162

[6] Baker DW, Stevens CD, Brook RH. Determinants of emergency department use by ambulatory patients at an urban public hospital. Ann Emerg Med. 1995; 25: 311-6. http://dx.doi.org/10.1016/S 0196-0644 (95) 70285-7

[7] Buesching DP, Jablonowski A, Vesta E, et al. Inappropriate emergency department visits. Ann Emerg Med. 1985; 14: 672-6. http: //dx.doi.org/10.1016/S0196-0644(85)80886-6

[8] Richardson LD, Asplin BR, Lowe RA. Emergency Department crowding as a heat policy issue: past development, future directions. Ann Emerg Med. 2002; 40: 388-393. PMid: 12239493. http://dx.doi.org/10.1067/mem.2002.128012

[9] Steinbrook R. The role of the emergency department. N Engl J Med. 1996; 334(10): 657-658. PMid: 8592532. http://dx.doi.org/1 $0.1056 /$ NEJM199603073341010

[10] Lambe S, Washington DL, Fink A, et al. Trends in the use and capacity of California's EDs, 1990-1999. Ann Emerg Med. 2002; 39: 389-396. PMid: 11919525. http://dx.doi.org/10.1067/mem .2002 .122433

[11] Derlet R, Richards J, Kravitz R. Frequent overcrowding in US emergency departments. Acad Emerg Med. 2001; 8: 151-155. PMid: 11157291. http://dx.doi.org/10.1111/j.1553-2712.2001 .tb01280.x

[12] Olshaker JS, Rathlev NK. Emergency department overcrowding and ambulance diversion: the impact and potential solutions of extended boarding of admitted patients in the emergency department. J Emerg Med. 2006; 30: 351-356. PMid: 16677993. http: $/ /$ dx.doi.org/10.1016/j.jemermed.2005.05.023

[13] Shull MJ, Kiss A, Szalai JP. The effect of low complexity patients on Emergency department waiting times. Ann Emerg Med. 2007; 49: 257-264. PMid: 17049408. http://dx.doi.org/10.1016/j . annemergmed .2006.06.027

[14] Treciak S, Rivers EP. Emergency department overcrowding in the United States: an emerging threat to patient safety and public health. Emerg Med J. 2003; 20: 402-405. http://dx.doi.org/10.1136 /emj . 20.5.402

[15] Pitts SR. Higher-Complexity ED Billing Codes - Sicker Patients, More Intensive Practice, or Improper Payments? N Engl J Med. 2012; 367(26): 2465-7. PMid: 23268662. http://dx.doi.org/10.10 56/NEJMp1211315

[16] Jencks SF, Williams MV, Coleman EA. Rehospitalisations among patients in the Medicare fee-for-service program. N Engl J Med. 2009; 360: 1418-1428. PMid: 19339721. http://dx.doi.org/10.10 56/NEJMsa0803563

[17] Boutwell A, Jencks S, Nielsen G, et al. State Action on Avoidable Rehospitalisations (STAAR) Initiative: Applying early evidence and experience in front-line process improvements to develop a state- based strategy. Institute for Healthcare Improvement. Cambridge, MA; 2009. Available from: http://www.ihi.org/Engage/Initiatives/Completed/STA AR/Documents/STAAR\%20State $\% 20$ Based\%20Strategy . pdf [Access Oct 2, 2014].

[18] Steiner C, Barrett M, Hunter K. Statistical brief of 90-hospital readmissions and multiple emergency department visits, in selected states, 2006-2007. Healthcare Utilization Project (HCUP). Available from: http://www.hcup-us.ahrq.gov/reports/statb riefs/sb90.jsp [Access Oct 2,2014].
[19] US General Accounting Office. Hospital Emergency Departments: Crowded Conditions Vary Among Hospitals and Communities. Washington, DC: General Accounting Office; 2003.

[20] McCaig LF, Burt CW. National Hospital Ambulatory Medical Care Survey: 2002 Emergency Department Summary. Advance Data from Vital and Health Statistics; No. 340. Hyattsville, MD: National Center for Health Statistics; 2004.

[21] Mirò O, Sanchez M, Coll-Vinent B, et al. Quality assessment in Emergency Department: behavior respect to attendance demand. Med Clin (Barc). 2001; 116(3): 92-7.

[22] Gilligan P, Joseph D, Winder S, et al. DNW-“did not wait" or "demographic needing work": a study of the profile of patients who did not wait to be seen in an Irish emergency department. Emerg Med J. 2009; 26(11): 780-2. PMid: 19850798. http://dx.doi.org/10. $1136 / \mathrm{emj} .2008 .063388$

[23] Darrab AA, Fan J, Fernandes CM, et al. How does fast track affect quality of care in the emergency department? Europ J Emerg Me. 2006; 13: 32-35. http://dx.doi.org/10.1097/00063110-200 602000-00008

[24] Ieraci S, Digiusto E, Sonntag P, et al. Streaming by case complexity: Evaluation of a model for emergency department Fast Track. Emerg Med Australas. 2008; 20: 241-249. PMid: 18462407. http://dx.doi.org/10.1111/j.1742-6723.2008.01087.x

[25] Considine J, Kropman M, Kelly E, et al. Effect of emergency department fast track on emergency department length of stay: a case-control study. Emerg Med J. 2008; 25(12): 815-9. http: //dx.doi.org/10.1136/emj. 2008.057919

[26] Health Ministry Decree, Gazette. Available from: http://www.ga zzettaufficiale.it/

[27] Guidelines, Health Ministry Decree, Gazette. Available from: http://www.ipasvi.it/archivio_news/leggi/238/ACC/ 251001.pdf

[28] Gruppo Formazione Triage: Triage Infermieristico. $2^{\text {nd }}$ edition McGraw-Hill Companies; 2005.

[29] King DL, Ben-Tovim DI, Bassham J. Redesigning emergency department patient flows: Application of Lean Thinking to health care. Emerg Med Australas. 2006; 18: 391-397. PMid: 16842310 http://dx.doi.org/10.1111/j.1742-6723.2006.00872.x

[30] Rodi SW, Grau MV, Orsini CM. Evaluation of a fast track unit: alignment of resources and demand results in improved satisfaction and decreased length of stay for emergency department patients. Q Manage Healthcare. 2006; 15: 163-170. http://dx.doi.org/10.10 97/00019514-200607000-00006

[31] Birnbaum A, Gallagher J, Utkewiccz M, et al. Failure to validate a predictive model for refusal of care to emergency department patients. Acad Emerg Med. 1994; 1: 213-217. PMid: 7621199. http: //dx.doi.org/10.1111/j.1553-2712.1994.tb02434.x

[32] King DL, Ben-Tovin D, Bassham J. Redisegning emergency department patient flows: Application of Lean Thinking to health care. Emerg Med Australasia. 2006; 18: 391-397. PMid: 16842310. http://dx.doi.org/10.1111/j.1742-6723.2006.00872.x

[33] Allo JC, Vigneau JF, Jang J, et al. Appropriateness of diagnosis and orientation of 996 consecutive patients admitted in an emergency department with a flow-based organization. Europ J Emerg Med. 2009; 16: 23-28. PMid: 18981928. http://dx.doi.org/10.1097/MEJ $.0 \mathrm{~b} 013 \mathrm{e} 32830 \mathrm{a} 992 \mathrm{~d}$

[34] Arbaje AI, Wolff JL, Yu Q, et al. Post discharge environmental and socioeconomic factors and the likelihood of early hospital readmission among community-dwelling Medicare beneficiaries. Gerontologist. 2008; 48: 495-504. PMid: 18728299. http: //dx.doi.org/10.1093/geront/48.4.495 
[35] Ashton CM, Kuykendall GH, Johnson ML, et al. The association between the quality of inpatient care and early readmission. Ann Intern Med. 1995; 22: 415-421. http://dx.doi .org/10.7326/0 003-4819-122-6-199503150-00003

[36] Kelly AM, Chirnside AM, Curry CH. An analysis of unscheduled return visits to an urban emergency department. N Z Med J. 1993; 106: 334-336. PMid: 8341474.
[37] Pierce JM, Kellerman AL, Oster C. "Bounces": an analysis of shortterm revisits to a public hospital emergency department. Ann Emerg Med. 1990; 19: 752-757. http://dx.doi.org/10.1016/S0196 -0644(05) 81698-1

[38] Medicare Payment Advisory Commission. Report to the Congress: Promoting Greater Efficiency in Medicare. Washington, DC: Medicare Payment Advisory Commission; 2007. 